\title{
Perceção das populações locais face à sustentabilidade dos serviços das zonas costeiras: o caso da Lagoa de Santo André, Portugal *
}

\section{Perception of the local population in the face of sustainability of coastal areas services: the case of Lagoon of Santo André, Portugal}

\author{
Armando José Santinhos ${ }^{@,}{ }^{\text {; }}$ Ana Paula Martinho ${ }^{1,2}$; Sandra Caeiro ${ }^{1,3}$
}

\begin{abstract}
RESUMO
Em Portugal, o reconhecimento da importância estratégica da zona costeira, criou a necessidade de proceder à sua proteção e gestão integrada. O litoral de Santiago do Cacém caracteriza-se por uma zona aplanada e baixa, que, devido à existência de um cordão de dunas e areias de praia na parte noroeste do concelho, isola do mar a sua bacia hidrográfica e linhas de água, dando lugar à formação de lagoas, como é o caso da Lagoa de Santo André. Nesta Lagoa tem nas últimas décadas existido um conflito de interesses entre estratégias de conservação dos valores naturais pelas autoridades e o uso pelas comunidades locais, que encontram neste ecossistema a realização de proveitos relevantes para a sua sobrevivência.

Tendo presente os conceitos de desenvolvimento sustentável, cidadania, participação e educação ambiental, este trabalho, através da conjugação de recolha de dados por inquérito, observação direta, pesquisa e análise documental, pretendeu contribuir para a perceção dos atores-chave envolvidos no processo, relativa à sustentabilidade dos ecossistemas da zona em estudo, tendo presente as várias realidades, interesses e sensibilidades grupais, e propor soluções para a melhor gestão da lagoa de Santo André.

Foi aprofundado o estudo de caso da Lagoa de Santo André, com particular destaque para a atividade de pesca artesanal na lagoa, tendo-se concluído, entre outros, a existência de problemática e contestação relativamente à gestão do ICNF (Instituto de Conservação da Natureza e Florestas), motivada por falta de diálogo e falha na comunicação entre os atores-chave do processo, bem como a falta de realização urgente do desenvolvimento de uma estratégia e de uma plataforma de entendimento que, ao nível dos decisores, promovam o desenvolvimento e a qualidade a todos os níveis desta zona do país de reconhecido potencial e que, simultaneamente, permitam com isso, a sua correta gestão.

Estes e outros aspetos foram tratados aprofundadamente na discussão de resultados deste estudo, tendo-se proposto, entre outros, o entendimento entre os atores-chave, a variados níveis, e a participação de entidade exterior que modere e facilite o diálogo entre os atores-chave, de acordo com os problemas encontrados e de acordo com as soluções discutidas e concertadas num workshop final.
\end{abstract}

Palavras-chave: gestão de áreas costeiras, participação das populações, gestão de conflitos, utilização de nassas.

\section{ABSTRACT}

In Portugal, the recognition of the strategic importance of the coastal zones lead to the necessity to proceed to its integrated protection and management. Santiago do Cacém coast line is characterized by a shallow plane area on the northwest of the district, giving the possibility of formation of lagoons, due to the existence of sand dunes and sand beaches, as it is the case of

\footnotetext{
(a) Corresponding author: santinhosarmando9@gmail.com

${ }^{1}$ Universidade Aberta, R. da Escola Politécnica, 147, Lisboa, Portugal

${ }^{2}$ Universidade Aberta, Laboratório de Ensino a Distância e e-learning (LEAD), Lisboa, Portugal

${ }^{3}$ Universidade Nova de Lisboa (UNL), Center for Environmental and Sustainability Research (CENSE), Monte da Caparica, Portugal
}

* Submission: 16 FEB 2014; Peer review: 13 MAR 2014; Revised: 28 APR 2014; Accepted: 2 JUN 2014; Available on-line: 16 SET 2014 
the Lagoon of Santo André. This lagoon has in recent decades been confronted with a conflict of interests between strategies of wildlife conservation authorities and the use by local communities that depend on this ecosystem for their survival.

Taking in account the ideas of sustainable growth, citizenship, ambient participation and education, and having gathered data through the combination of enquiry, direct observation, and documental search and analysis, this work pretends to contribute for the knowledge of the perception of the people and local officials in face of the sustainability of the ecosystems services used by the population.

This case study of the Lagoa de Santo André has given special consideration to the activities of the traditional fishing methods in the lagoon, having been concluded, among other issues, the existence of problems and controversy about the management of the ICNF (Institute of Nature Conservation and Forests) due to lack of dialogue and failure in the communication between the main actors of the process, the lack of a strategy or an environmental, economic, seaside management plan that would foment the quality at all levels of this zone of the country of recognized potential. The study urges to restore conducts that avoid the environmental degradation of this lagoon ecosystem and the development of a broader consensus about the regulations in place, so that standard decisions may be taken in order to establish the participation and cooperation of all agents and actors in the decision process.

These and other aspects were deeply treated on the final discussion of this study, having been proposed, among others, the promotion of an understanding between the key-actors, at various levels, and the participation of outside entity to moderate and facilitate the dialogue among the stake-holders, according to the problems encountered and according to the solutions discussed and to be concerted in a final workshop.

Key-words: management of coastal areas, participation of populations, conflict management, use of fish traps.

\section{Introdução}

A humanização impõe a necessidade de uma correta gestão das zonas costeiras como forma de, presumivelmente melhorar o nível de exploração dos recursos naturais. Todavia, a Natureza gere-se a si própria com extrema eficácia, garantindo verdadeira sustentabilidade para o futuro a curto, médio, longo e muito longo prazos. Ao longo dos cerca de 4,5 mil milhões de anos de vida na Terra os ecossistemas foram-se sucedendo, tornando-se progressivamente mais complexos (Dias et al., 2012).

Assim, ao tentar assumir-se como entidade reguladora dos processos dos quais depende, mas que conhece ainda mal e que, efetivamente, não controla, o Homem entrou em conflito consigo mesmo. E esses conflitos são evidentes na exploração dos recursos marinhos, nunca sendo demais relembrar que o litoral é o principal recurso marinho explorado na atualidade (Dias et al., 2012).

São inúmeros os estudos em todo o mundo onde se observa a insustentabilidade das zonas costeiras devido à elevada pressão urbana e má gestão dos serviços dos ecossistemas costeiros.

Wakashima \& Capellari (2010) efetuaram um estudo sobre globalização e deslocalização, numa análise sobre o crescimento do turismo residencial no Mediterrâneo espanhol e no litoral do Nordeste brasileiro e os seus efeitos socioambientais, os impactos do turismo residencial, bem como a sua evolução, analisando as características desta atividade, tanto na perspetiva do Brasil como em relação à Espanha. Segundo os autores, de entre as diversas segmentações do turismo no Brasil, está em ascensão, principalmente no Nordeste, o denominado turismo residencial. Esta atividade caracteriza-se pela utilização de segunda residência localizada em praias e centros urbanos, para fins de lazer. O Litoral Mediterrâneo Espanhol é um dos destinos onde o turismo residencial está mais fortemente consolidado; porém, sofre com a saturação dos espaços e o comprometimento da qualidade ambiental, tornando insustentável a economia local. A especulação imobiliária fez em ambos os casos, com que famílias optassem por morar em regiões periféricas, muitas vezes em condições de insalubridade. A chegada de mega-investimentos, principalmente os estrangeiros, ocasionou a descaracterização de cultura local, na qual se inclui naturalmente a atividade piscatória. A estrutura disposta por estes empreendimentos consome muito mais recursos naturais, se comparados a simples hotéis e pousadas, além de descaraterizar a paisagem, comprometendo assim o principal atrativo turístico da região (Wakashima \& Capellari, 2010).

A alteração da composição demográfica, causada pelos processos migratórios de trabalhadores e turistas; o desaparecimento das atividades tradicionais e da cultura local; e a transformação da paisagem; são estes alguns impactos presenciados pelas comunidades localizadas no Mediterrâneo, bem como no Nordeste brasileiro, que acabam ocasionando a decadência de suas atrações turísticas, estimulando assim a busca por lugares menos saturados, prestando com isto um contributo de valorização para o conhecimento e com isso para o estado da arte sobre estas matérias (Wakashima \& Capellari, 2010).

Leal (2012), na sua dissertação sobre as experiências vivenciadas por duas comunidades, Canoa Quebrada e Vila do Estevão, numa análise sobre a perceção dos diferentes atores sociais sobre o processo de modernização vivido por essas populações, contextualizou a formulação de uma análise sociológica, acerca da civilização e do capital, em tempos 
contemporâneos, estabelecendo uma relação entre modernização e o modo de vida das comunidades tradicionais da zona costeira cearense. A autora refere que o seu estudo se pautou por uma metodologia qualitativa, tendo as investigações seguido as vias da observação e realização de entrevistas temáticas, identificando os impactos provocados pela tensão social imposta através do modelo de desenvolvimento vigente, com os seus padrões impositivos, muitas vezes em antítese com aspetos relativos ao comportamento dos povos e das suas tradições.

A autora refere ainda que a problemática em estudo tem vários pontos de contacto com outros debates atualmente em curso nas ciências sociais e humanas, e que, por isso, se dispõe de um dispositivo teórico amplo, que abarca a pluralidade de conceções e perceções sobre as relações entre trabalho, tempo e ócio, os paradigmas da tradição e da modernidade e as estratégias de enfrentamento das organizações coletivas pela coexistência com essa realidade. Nesse contexto, a autora utiliza como suporte teórico, a sociologia das ausências e a sociologia das emergências, as conceções de tempo social assim como os conceitos sobre a crise estrutural do capital e sua estrutura fundante (Leal, 2012).

A autora considera que a modernidade é a base racional, científica, que surge como verdade absoluta para o conhecimento, bem como para a explicação dos fenómenos da natureza. Para os povos que a enfrentam, é um momento de transição em que o divino deixa de compor a base explicativa desses fenómenos, enquanto a razão pura passa a fazer parte desse cenário, buscando-se a razão e explicação científicas e negando-se as crenças desprovidas de comprovações (Leal, 2012).

Portugal possui cerca de $1450 \mathrm{~km}$ de costa e mais de metade da população portuguesa vive em concelhos do litoral. Assim, a correta gestão das Zonas Costeiras é decisiva para o desenvolvimento do país.

Segundo a Estratégia Nacional para a Gestão Integrada da Zona Costeira de Portugal aprovada pela Resolução do Conselho de Ministros n. ${ }^{\circ}$ 82/2009, as zonas costeiras assumem uma importância estratégica em termos ambientais, económicos, sociais, culturais e recreativos, pelo que o aproveitamento das suas potencialidades e a resolução dos seus problemas exigem uma política de desenvolvimento sustentável apoiada numa gestão integrada e coordenada dessas áreas.

Tendo presente que, de acordo com Gerhardt \& Almeida (2005), os problemas biofísicos e de sustentabilidade, no âmbito costeiro, passam por uma inspiração de "movimento ambientalista", e sendo o ambiente também uma problemática social, será relevante incluir esta questão dentro de um processo dinâmico de reestruturação sociocultural, estando em jogo (em disputa) no contexto da própria modificação, a forma como a sociedade se organiza, pensa e elabora seus valores, bem como as suas prioridades e desejos.

A Lagoa de Santo André (Fig. 1) é exemplo onde a gestão das zonas costeiras não é uma tarefa fácil, onde as pressões das atividades piscatórias da população local têm de se conciliar e equilibrar com os valores naturais e de biodiversidade. Esta zona costeira integra a Reserva Natural da Lagoa de Santo André e da Sancha, através de Decreto-Regulamentar n. ${ }^{\circ}$ 10/2000 de 22 de agosto, onde é referido que foi finalmente reconhecida a importância deste santuário natural.

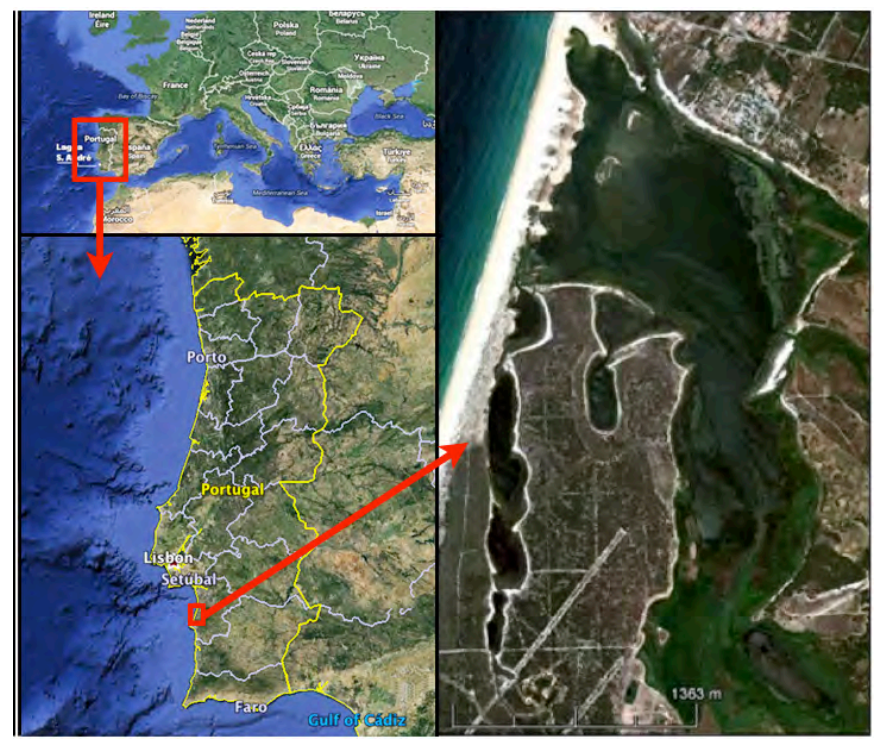

Figura 1 - Planta de Localização

Figure 1 - Location of Plant

Este trabalho tem como objetivo geral contribuir para caraterizar a perceção da população local face à sustentabilidade dos ecossistemas da zona costeira em estudo, utilizados por essa população, bem como, num processo de cidadania participativa, envolver todos os atores na construção de soluções e de consensos, tendo presente as fragilidades encontradas, as várias realidades, interesses e as sensibilidades grupais aduzidas no decorrer deste estudo exploratório.

Como objetivos específicos, pretendeu-se:

i) Identificar e caraterizar o estado das atividades piscatórias na Lagoa de Santo André, incluindo a sua evolução histórica em termos das alterações físicas do ecossistema, de ordenamento, das artes de pesca, cultura, tradição, registo do volume e principais espécies capturadas.

ii) Avaliar a perceção da população local e dos decisores em relação aos fatores que de alguma forma contribuíram para um processo de mudança no âmbito das suas valências socioeconómicas e de tradição, com enfoque especial para a atividade da pesca na lagoa.

iii) avaliar a perceção da população sobre os mecanismos utilizados para a resolução dos fatores 
mencionados, nomeadamente no que se refere à necessidade de ordenamento da orla costeira ou à sustentabilidade do ecossistema da Lagoa de Santo André, entre outros.

iv) Propor soluções, medidas e recomendações para garantir o equilíbrio entre a atividade económica local da pesca, a sustentabilidade e a harmonia do ecossistema em estudo.

\section{Material e métodos}

\subsection{Enquadramento Metodológico}

Neste trabalho foi utilizada uma metodologia de estudo de caso, maioritariamente qualitativa, com base na pesquisa e análise de documentos escritos e orais, bem como na recolha de informação por inquérito e por questionário aos pescadores locais, numa amostra o mais abrangente possível da população; foram, ainda, realizadas entrevistas a agentes e decisores; a esta fase, seguiu-se, após estudo e interpretação da informação recolhida, a organização de um "workshop" com os principais atores-chave da região, nomeadamente, os pescadores e sua associação, os empresários da restauração local, edilidades, autoridades e organismos de proteção da natureza. O objectivo deste encontro centrou-se na discussão e votação de um conjunto de problemas no âmbito da pesquisa efetuada pelo autor, no sentido de se encontrarem soluções, obtidas por votação dos atores-chave presentes.

Este estudo de caso assenta numa premissa com uma dupla vertente: por um lado, é uma modalidade de investigação apropriada para estudos exploratórios e abrangentes e que, sobretudo, tem como objetivo a descrição de uma situação, a explicação de resultados a partir de uma teoria, a identificação das relações entre causas e efeitos ou a validação de teorias (Serrano, 2004). Por outro lado, permite ilustrar e analisar uma dada situação real e fomentar a discussão e a tomada de decisões, julgadas convenientes para a mudar ou melhorar.

Para melhorar a compreensão dessas realidades complexas, contrapõe-se a uma perspetiva quantitativa uma abordagem qualitativa de pesquisa que tem como objetivo a compreensão dos significados atribuídos pelos sujeitos às suas ações num dado contexto. Nesta abordagem, pretendeu-se interpretar em vez de medir, procurando-se caraterizar a realidade experienciada pelos sujeitos ou grupos a partir do que estes pensam e da forma como agem (seus valores, representações, crenças, opiniões, atitudes e hábitos).

As investigações qualitativas privilegiam, essencialmente, a compreensão dos problemas a partir da perspetiva dos sujeitos da investigação. Neste contexto, Bogdan \& Biklen (1994), consideram que esta abordagem permite descrever um fenómeno em profundidade através da apreensão de significados e dos estados subjetivos, pois, nestes estudos, há sempre a tentativa de capturar e compreender, com pormenor, as perspetivas e os pontos de vista dos indivíduos sobre determinado assunto. Pode-se dizer que o principal interesse destes estudos não é efetuar generalizações mas antes particularizar e compreender os sujeitos e os fenómenos na sua complexidade e singularidade. Assim, em oposição às afirmações universais e à explicação dos fenómenos numa causalidade linear, preferiu-se, neste projeto, a descrição concreta das experiências e das representações dos sujeitos que conduzem a uma compreensão dos fenómenos.

De acordo com os objetivos enumerados anteriormente, o trabalho foi dividido em três tarefas: 1) Caracterização das atividades piscatórias; 2) Perceção dos Pescadores; 3) Propostas de soluções e recomendações.

\subsection{Tarefas Desenvolvidas}

\subsubsection{Caraterização da Atividade Piscatória}

A metodologia de investigação centrou-se numa primeira abordagem na recolha de informação, derivada da pesquisa de documentação e literatura existente, bem como pesquisa por documento não escrito, de modo a ser possível caraterizar o estudo de caso e em particular o estado da atividade piscatória na Lagoa de Santo André, incluindo a sua evolução histórica em termos de artes de pesca, cultura e tradição, evolução do ecossistema litoral, quais as principais espécies capturadas e a importância de estratégias de investimento para a economia local.

Para o efeito foram efetuadas entrevistas a um conjunto reduzido de atores-chave locais, que subsistem no terreno e fazem parte da atual povoação (Anexo I), bem como aos organismos tutelares da zona costeira e da conservação da natureza (Anexo II), para que estes nos evidenciassem processos e/ou projetos, ainda que em área de planeamento, com vista ao desenvolvimento sustentável da região.

\subsubsection{Perceção dos Pescadores}

Numa segunda fase do trabalho procedeu-se ao inquérito por questionário à população piscatória (Anexo III), para análise dos dados recolhidos e trabalhados em gabinete.

O objetivo deste inquérito foi avaliar a perceção desta população quanto à continuidade e sustentabilidade da pesca no ecossistema da Lagoa de Santo André, bem como apurar a sua sensibilidade, no âmbito sócioeconómico e ambiental, às alterações trazidas pelo ordenamento.

De acordo com Quivy \& Capenhoudt (1998), o inquérito por questionário consiste em colocar a uma amostra de indivíduos de uma determinada população, que os mesmos representam, uma série de perguntas, relativas à sua situação social, académica, profissional 
ou familiar, às suas opiniões, à sua atitude em relação a variadíssimas questões humanas e sociais, às suas expectativas perante um determinado acontecimento, ao seu nível de conhecimento ou de consciência relativos a um problema, ou, ainda, sobre assuntos que possam interessar ao processo de investigação.

O preenchimento destes questionários foi confidencial. Pretendeu-se, de igual modo, perceber o papel do cidadão, do pescador, enquanto parte interessada, no sentido da perceção da sua capacidade para se organizar grupalmente e em que medida consegue nessa participação a tradução da sua força representativa e da sua vontade coletiva.

\subsubsection{Proposta de Soluções e Recomendações}

Numa terceira fase organizou-se um "workshop" com os atores-chave, onde se apresentou os resultados obtidos nas tarefas anteriores, com vista à discussão em conjunto das soluções, das medidas e das recomendações que garantissem modelarmente a atividade económica local da pesca versus a sustentabilidade e o equilíbrio do ecossistema.

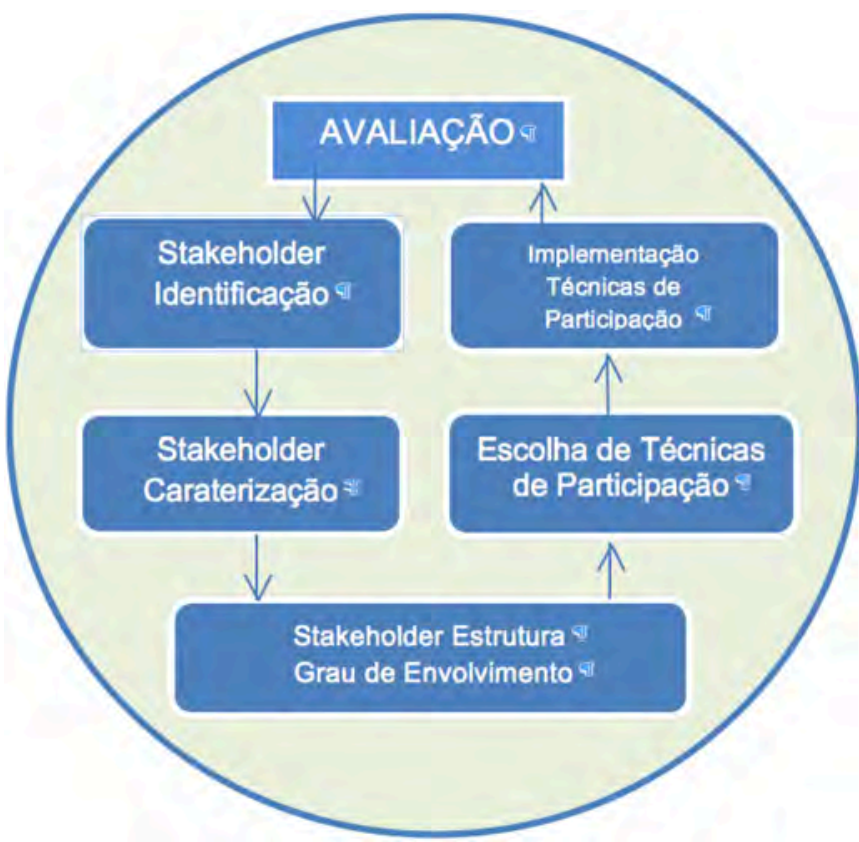

Figura 2 - Proposta de Quadro de Participação dos Atoreschave. Adaptado de Luyet et al (2012)

Figure 2 - Proposal for a Framework Participation of Stakeholders. Adapted from Luyet et al (2012)

No âmbito de um quadro de referência (framework) relativo a técnicas de participação com vários graus de envolvimento das partes, considerámos que, de entre as várias técnicas que congregam Consulta, Colaboração, Decisão Partilhada e Responsabilização, entre as quais destacamos "Consensus Conference", "Scenario Analysis", "Citizen Jury", a técnica que mais se adequa à gestão de conflitos é, sem dúvida, a realização de um workshop. Para tal, e de acordo com os autores Luyet et al. (2012), adotámos a proposta que abaixo explicitamos (Fig. 2), no sentido de uma melhor compreensão do processo da participação dos atoreschave e como, por maioria de razão, se ajustam a este trabalho.

$\mathrm{Na}$ identificação dos atores, tivemos em conta os vários papéis designados técnicos e que envolvem critérios tais como a proximidade, a economia, os valores sociais e ambientais.

No âmbito da sua caracterização, sustenta-se a possibilidade de existirem múltiplas e variadas atitudes perante o projeto, em particular as que resultam do ponto de vista da Reserva Natural, e as dos demais atores, que, estando em contexto de diferentes sensibilidades, poderão potenciar conflitos.

Este workshop sobre a Lagoa de Santo André assentou num exercício de cidadania participativa, cuja metodologia encontra sustentação de acordo com o método anteriormente descrito, sobre o quadro de atores-chave.

O universo de outros trabalhos na área do ordenamento costeiro, nos quais a participação das populações foi determinante para a obtenção de consensos e cuja problemática exigia intervenção e consensualização de procedimentos, serviu de complemento neste processo, sendo a metodologia utilizada para a elaboração e organização do workshop baseada nos critérios de Vasconcelos (2006) e Vasconcelos \& Caser (2011).

\section{Caso de Estudo - Lagoa de Santo André}

\subsection{Contexto Histórico - Pesca}

Segundo Madeira (1993), por volta de 1855, pescadores de Ílhavo e respetivas famílias chegaram à Costa de Santo André, tendo aí construído as suas cabanas e armazéns de colmo e caniço (Fig. 3).

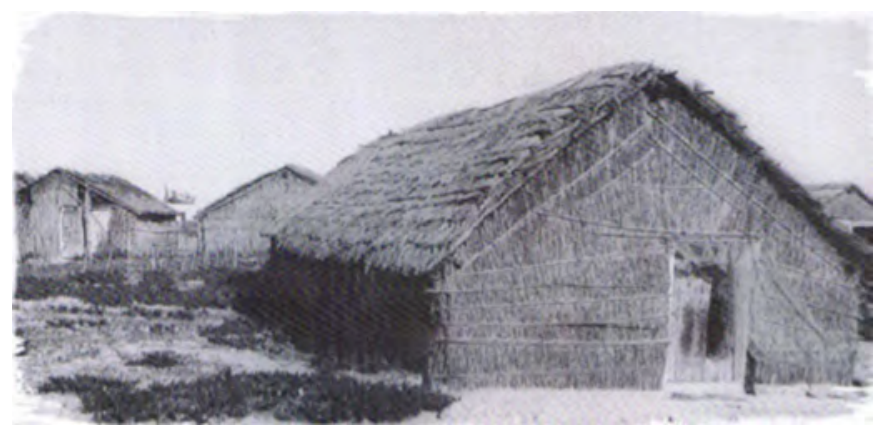

Figura 3 - Habitações de caniço e mato. Extraído de Escoval et al. (2003).

Figure 3 - Dwellings of Reeds and Weeds. Extracted from Escoval et al. (2003). 
Devido à abundância de sardinha no mar (no Verão) e outro peixe na lagoa (no Inverno), terão estabelecido duas companhas com lavradores da região, praticando a arte xávega (Fig. 4). Na praia da freguezia de Santo André se acham estabelecidas ha seis annos duas companhas de pescadores de Aveiro, que também carregam anualmente de sardinha bom numero de embarcações costeiras com destino para diversos portos do reino (Silva, 1869: 104).

Segundo Madeira (1993), convém distinguir entre a pesca na lagoa e a pesca no mar, através dos seus barcos saveiros, preparados para a arte de xávega, que foi introduzida pelos oriundos do Centro Norte (Ílhavo, Aveiro e Murtosa) por volta de 1855 e que perdurou até cerca dos anos cinquenta e princípio de sessenta do século XX.

Quanto à pesca no mar, com bastante expressão, em que subsistiam duas campanhas para os lanços de mar, conclui-se um relativo desenvolvimento desta faina ao verificar-se que em 1875, no recenseamento eleitoral, de base censitária, constavam quatro pescadores coletados, com movimentos financeiros entre 1000 e 6333 réis de décima, valores para rendimento bruto bastante consideráveis à época (Madeira, 1993).

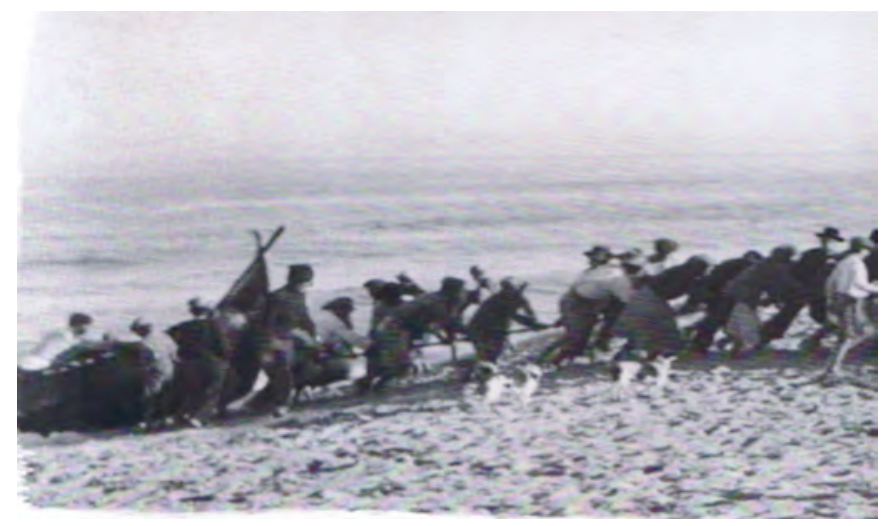

Figura 4 - Arte xávega. Extraído de Escoval et al. (2003).

Figure 4 - Xávega art. Extracted from Escoval et al. (2003).

A pesca na lagoa torna-se a alternativa para a subsistência das famílias de pescadores em período invernoso e, simultaneamente, à medida que se dá o declínio da arte de xávega, ganha maior expressão e acentua a sua importância (Fig. 5).

A apanha de enguias é a arte de maior relevância na pesca da lagoa, tendo-se tornado progressivamente a sua captura principal. A restante pesca, relativa a outras espécies e pouco relevante em termos de dados objetivos e estatísticos, era complementar à pesca da enguia, sendo muitas vezes destinada ao consumo próprio de pescadores e suas famílias. Para termos em conta um valor aproximado das capturas, o rendimento médio anual, até meados do século XX, era de 150 $\mathrm{kg} / \mathrm{h}$ ectare/ano, ou seja, um total de pescado de mais de 20 toneladas ano (Fonseca et al., 1993).

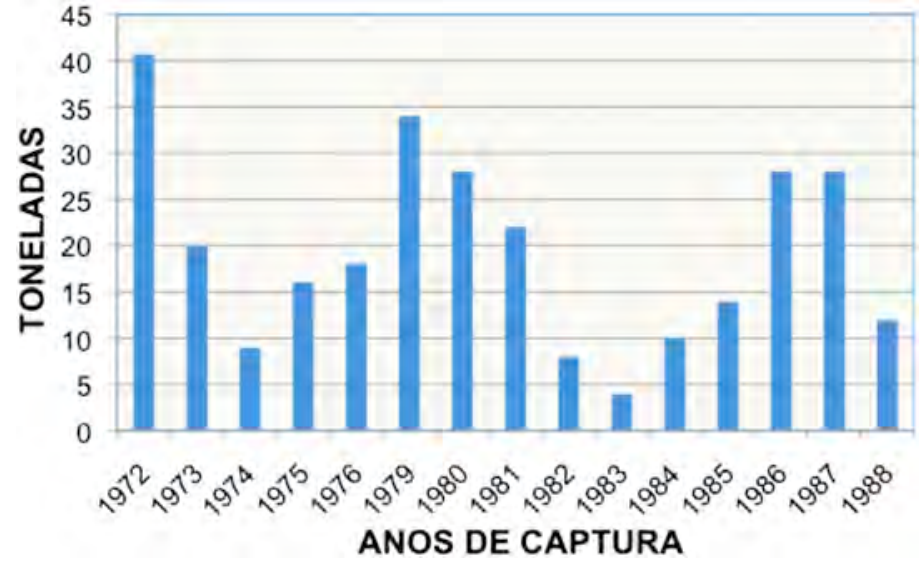

Figura 5 - Gráfico Síntese das Capturas na Lagoa de Santo André, entre 1972 e 1988. Baseado em dados de Fonseca et al. (1993).

Figure 5 - Summary of catches in Santo André Lagoon between 1972 and 1988. Based on data from Fonseca et al. (1993).

\subsection{Enquadramento}

A Lagoa de Santo André localiza-se no sudoeste de Portugal, no Distrito de Setúbal, região do Alentejo e sub-região do Alentejo Litoral, ocupando parte da costa do município de Santiago do Cacém.

Em meados do século XVII, a duna de areia que separa a lagoa do mar já se havia formado, adiantando que as ribeiras de que fala Frei Bernardo Falcão continuavam a descer a serra, sem desaguarem no mar, retendo-se nesse grande espaço de águas paradas, onde a grande enseada se tornava lagoa (Madeira, 1993).

Em termos gerais, segundo o estudo inicial para o Plano de Ordenamento da Reserva Natural das Lagoas de Santo André e Sancha (ERENA, 2005), a lagoa é constituída essencialmente por um conjunto de ecossistemas litorais e sublitorais, detendo como elemento principal o sistema lagunar.

Neste contexto, o corpo lagunar de Santo André é particularmente bem desenvolvido e ocupa uma superfície alagada de 150-250 ha, a qual pode duplicar durante o período invernal, devido à entrada de água proveniente das chuvas, da agitação e da ondulação do mar em época de tempestades. A lagoa dista escassas dezenas de metros do mar, sendo separada por um cordão dunar de largura e desenvolvimento variáveis (ERENA, 2005).

Quando, por imperativo das cheias de Inverno, o seu volume hídrico aumenta exponencialmente, é feita uma ligação ao mar, estabelecida artificialmente, quase sempre no mês de março, através de um canal que permanece aberto durante cerca de um ou mais meses, enquanto as condições de mar o permitirem (ERENA, 2005).

O caráter salobro das suas águas provém do maior ou menor tempo de contacto com o mar aquando do 
período da sua abertura, o que lhe confere um estatuto especial qualitativo, tendo em vista a apreciação do seu pescado e a qualidade das suas águas de teor salino e de apetência balnear, cujo valor de salinidade, em média representa - 10 a $20 \%$ (Fonseca et al., 1993).

\subsection{A Pesca na Atualidade}

$\mathrm{Na}$ determinação de uma zona de pesca profissional na Lagoa de Santo André, foi tido em conta o facto de esta atividade pesqueira ser uma realidade socioeconómica de importância considerável para a população e, também, a necessidade de regulação da gestão ambiental dada a intensidade dessa atividade profissional, tendo em vista o ordenamento e a conservação dos seus valores naturais (Portaria $\mathrm{n}^{\circ}$ $86 / 2004$ de 8 janeiro). A área de pesca autorizada consta de numa linha poligonal, referenciada, de acordo com a planta, e que une os pontos coordenados de 1 a 15 (Fig. 6.). Ou seja, com a criação da Reserva Natural, inicia-se um processo, em que, para atividades específicas como a pesca, o diploma atrás referido estabelece a possibilidade de se publicarem portarias conjuntas com outros ministérios, por forma a determinar condicionamentos ou interdições a esta atividade, iniciando com isso o processo de regulação da pesca na lagoa, o qual desencadeou a contestação dos pescadores.

Foi realçada a interpretação dos dados relativos ao volume do pescado declarado (Fig. 7), por comparação com os elementos históricos, nos quais se encontrou uma proporcionalidade digna de registo, ou seja, os totais atuais situam-se $36 \%$ dos totais anteriores ( 8 t, para $22 \mathrm{t} / \mathrm{ano}$ ), levando a questionar, embora isentando os aspectos conclusivos tratados posteriormente, a relação entre pescadores e pesca versus sustentabilidade e legislação. Segundo o ICNF, o número de pescadores com licenças atribuídas, desde 2004 não tem sofrido alteração digna de nota, centrando-se este valor em cerca de trinta e cinco a quarenta atribuições anualmente.

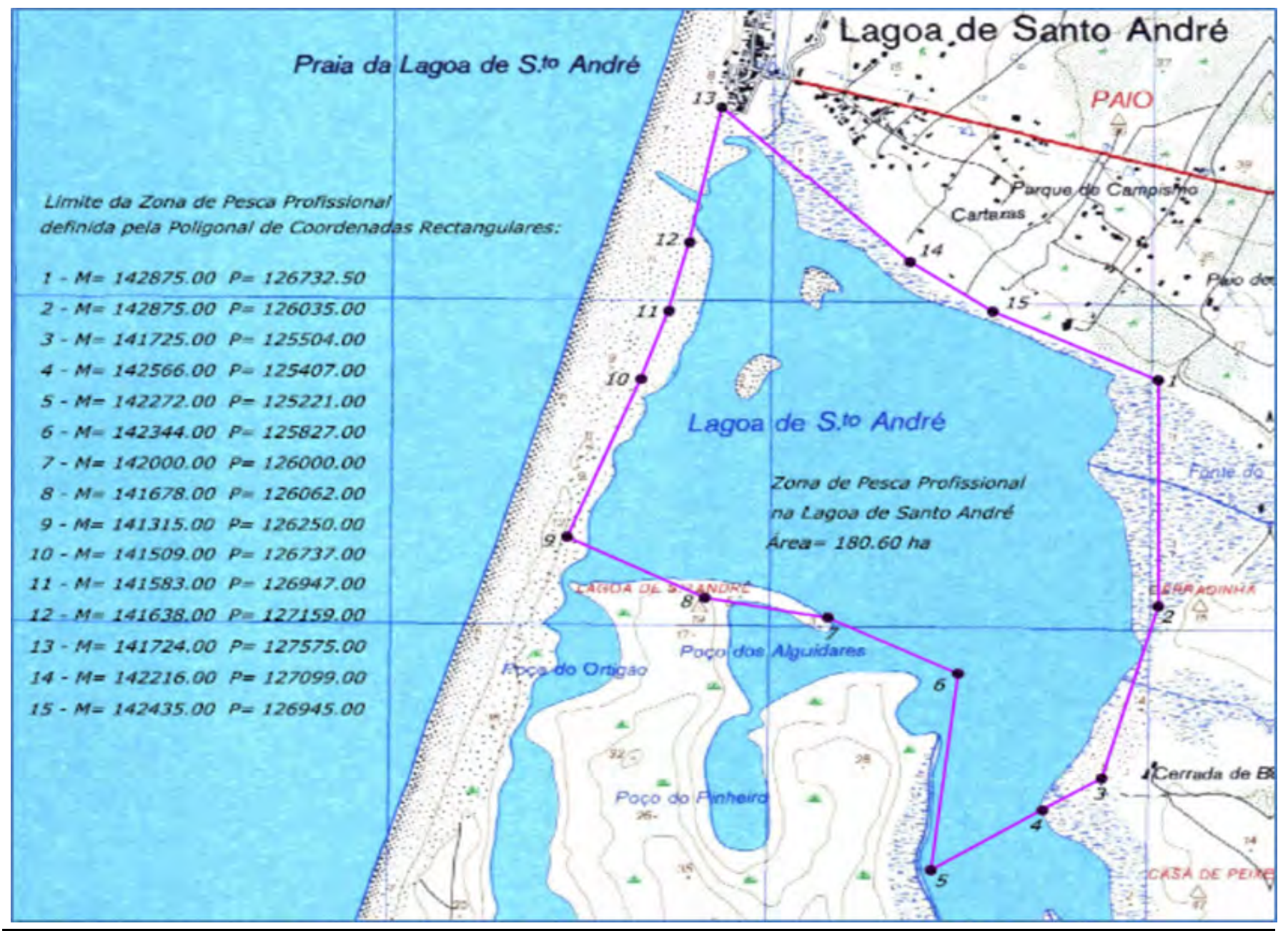

Figura 6 - Área Pesca Autorizada, segundo a Portaria n ${ }^{\circ}$ 86/2004 de 8 janeiro Figure 6 - Permited Fishing Area 


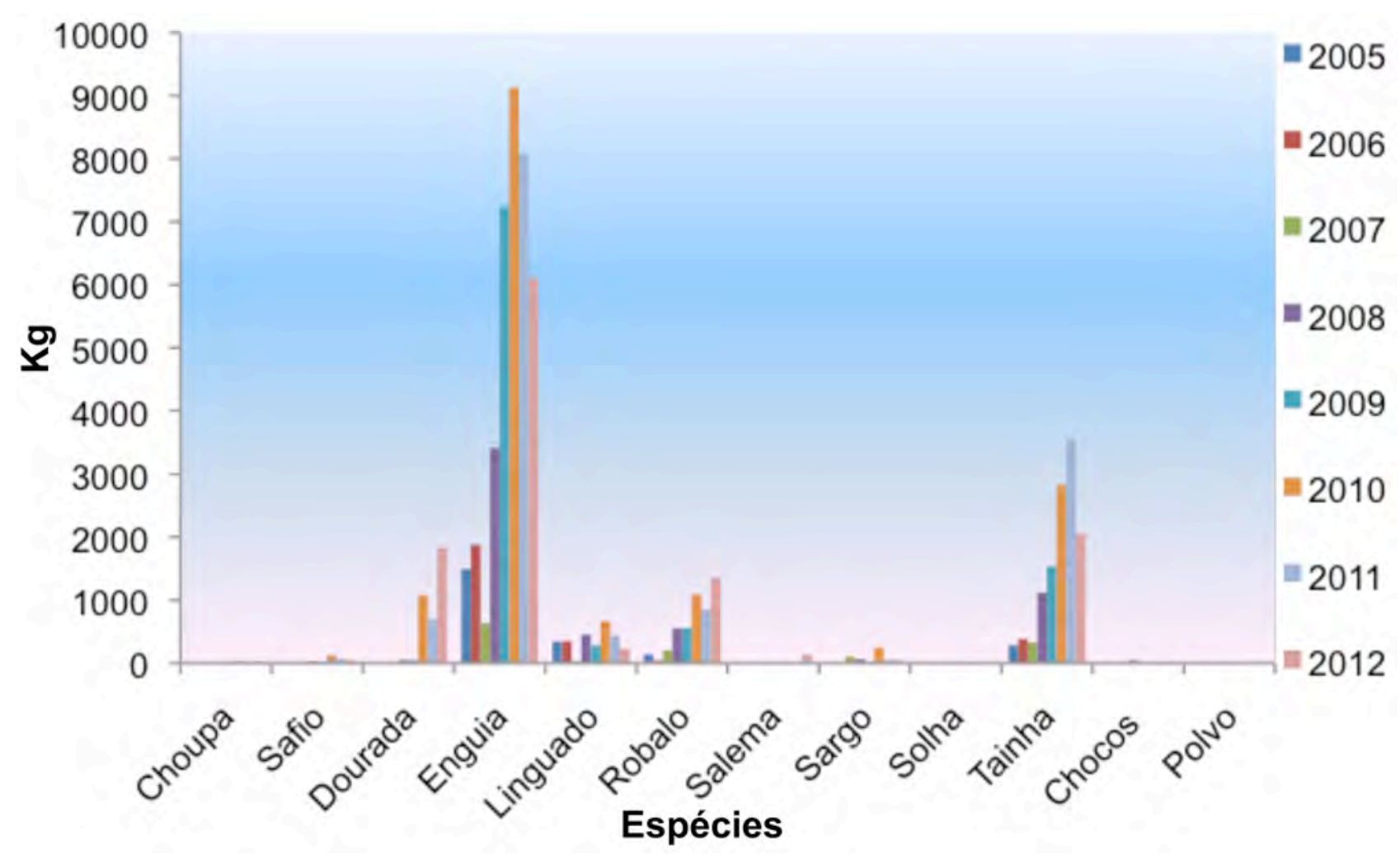

Figura 7 - Gráfico Síntese das Capturas Declaradas na Lagoa S.to André. Baseado em dados do ICNF Figure 7 - Summary of Catches in S.to André Lagoon

\section{Resultados e discussão}

\subsection{Entrevista à População Local}

No âmbito da entrevista semiestruturada à população da Lagoa de S. André - leia-se população piscatória e não outra - e uma vez que restam nesta localidade umas seis famílias de pescadores, houve que credibilizar os seus relatos, através de dois deles, os mais esclarecidos, dos pescadores mais antigos e mais aptos nos seus relatos, que a memória aflora de forma brilhante, sobre a prática da pesca da arte xávega no mar e o seu términus. Depois, foi preciso perceber o transporte desta arte para a pesca na lagoa, considerando a alteração das suas dimensões, para um formato muitíssimo menor, com uma malhagem também mais reduzida (malhagem de traineira), mas mantendo o cerco e o saco na proporcionalidade dos alares, o denominado chinchorro, ou chincha e a inclusão de novos aparelhos, as nassas. Foi também abordada a questão do abandono da atividade pelos pescadores e a falta de expectativas geradas pela ausência de planos de investimento e de desenvolvimento sustentáveis, que estes reclamaram de forma vincada no seu testemunho.

Uma particularidade interessante do relato de um dos pescadores entrevistados é que, de facto, "o fim da arte de xávega no mar acontece por volta dos anos sessenta do século XX". Ele próprio relata ainda ter insistido, em 1974, na compra de uma arte semelhante, "de menor porte", utilizando agora um "saveiro" mais curto, e teria assim tentado relançar esta tradição milenar; mas, por imperativo da sua proibição, uma meia dúzia de anos depois seria ele o último mestre, que encerraria definitivamente a campanha de pesca no mar na Costa de Santo André (Caniço, com. pess.).

Com o fim desta arte, que se tinha verificado anos antes desta sua aventura de reinventar a xávega, "já parte dos pescadores profissionais demandavam a pesca de mar em Sines, ficando os restantes a pescar na lagoa por conta de rendeiros, cuja exploração por concessão finda com a queda do Estado Novo, ou seja na revolução de abril de 1974". O que se constata das declarações de Caniço é que, mesmo tendo em conta o decréscimo gradual de pescadores na zona, cujo êxodo é sentido na década de sessenta do século XX, dado o volume de pescado extraordinariamente abundante na lagoa, mesmo sem a xávega no mar, "os pescadores, em alternativa, utilizam nos seus lances a arte de pesca de cerco, através da utilização de chinchorros curtos na lagoa" (Caniço, com. pess.).

A ausência de alternativas à atividade da pesca é clara no seguinte comentário: "temos muita pena que não haja projetos para desenvolver aquilo..., não fazem nada, nem para os banhistas, nem para os homens dos restaurantes, nem acessos, nada, poderia até ajudar o pescador, não é verdade? Agora vejam o estado a que chegou a zona da antiga povoação, é uma vergonha. Não pensam no desenvolvimento, é só promessas e andamos nisto há anos e anos; como é que uma pessoa 
resolve a vida sem ser na pesca? Não há alternativas" (Caniço, com. pess.).

Em síntese, poderemos inferir que, com o fim da arte antiga de pesca de cerco no mar da Costa de Santo André, ou arte xávega, cujas companhas envolviam os pescadores locais em número bastante considerável, e, naturalmente, por falta de recursos e de estímulo para continuar, parte desta gente procura formas alternativas de pesca noutros lugares. Os que ficam passam a dedicar-se à pesca na lagoa, agora não apenas como alternativa nos Invernos tempestuosos, mas como recurso possível, por conta dos rendeiros locais, no período permitido por lei. A arte utilizada, mais não era do que a chincha, igualmente uma pesca de cerco, agora reduzida nas suas dimensões, sem a exigência de contingentes ou companhas como as que eram necessárias para a faina no mar, bastando uma meia dúzia de homens por arte para os lances na lagoa.

\subsection{Entrevista a Decisores Locais}

Inquirida a chefia de Divisão da Gestão Urbanística da CMSC (Câmara Municipal de Santiago do Cacém), esta respondeu ter conhecimento de um plano de pormenor "aprovado irá para mais dez anos, com uma visão voltada para o turismo mas que, dadas as condicionantes socioeconómicas anteriores e vigentes, não foi possível avançar no terreno, dadas as onerosas infraestruturas necessárias e incomportáveis para o município em termos financeiros e pela inexistência de parcerias com entidades privadas" (Grade, com. pess.).

Em contrapartida, o ICNF, na pessoa de um dos seus técnicos superiores, sobre o mesmo assunto, referiu "desconhecer qualquer plano de reabilitação ou de promoção da economia local, adiantando estar em curso para breve, a criação de uma carta de desporto na natureza, reguladora de atividades de animação ambiental, turística e desportiva" (Nogueira, com. pess.).

Tais declarações são reveladoras da ausência de uma estratégia coerente para o desenvolvimento económico da região, em particular nas artes de pesca sustentável.

\subsection{Questionário aos Pescadores}

Tendo presente a metodologia da investigação adotada neste estudo, salientamos neste capítulo os principais problemas identificados pelos pescadores na pesca na Lagoa de Santo André e também a notória perda de qualidade ambiental a que a lagoa está sujeita.

Aduzem os pescadores de forma síncrona que as áreas marcadas para o exercício da pesca são calculadas em função do afastamento exagerado das margens da lagoa, e que a posição dos marcos delimitadores leva, por vezes, a que surjam erros de posição na colocação dos seus aparelhos de pesca, sujeitando-os a pesadas multas.
Também referem os mesmos pescadores, que tais coordenadas os colocam em zonas de pouco pescado e fundos exagerados, e que deveria haver uma maior aproximação a terra, em função da volumetria da lagoa, que é variável ao longo do ano; "andam com uns aparelhos de medir, os tais GPS e uma pessoa quando sabe, ou não sabe, tá a levar com eles" (Inquirido $n^{\circ} 2$ ).

Explicando, referem, a área em que lhes é permitido pescar, detém grande profundidade e tendo os alares das nassas a altura de 1 pano ( $2 \mathrm{~m}$ aprox.), o peixe não é canalizado eficazmente para o saco da captura; "querem é acabar com os pescadores e que a gente morra ali. Quem é que consegue espetar uma cana numa fundura daquelas? Não percebem nada de nada e não ouvem a gente" (Inquirido $\mathrm{n}^{0}$ 22). "Tal seria ultrapassado, deixando pescar mais junto às margens, orientando o pescador as dimensões destes aparelhos, em função da necessidade da pesca e não por imposição avulsa e prejudicial, o pescador é que sabe e escolhia a rede segundo e conforme a posição junto à terra" (Inquirido $\left.\mathrm{n}^{\mathrm{o}} 19\right)$.

Uma opinião comum dos pescadores, é de que a lagoa necessita ser desassoreada de forma cirúrgica, sob pena de daqui a poucos anos, a termos apenas na memória, transformando-se num charco infecto, se não forem tomadas medidas urgentes.

Apontam entre outras razões, a falta de limpeza dos cursos de água que nela desaguam, não permitindo o seu enchimento em plenitude, a falta de fiscalização relativa a descargas de efluentes nas suas ribeiras, com a consequente deposição de matéria lodosa no seu fundo. A isto acrescentam a abertura ao mar em condições pouco estudadas, em que o fecho da lagoa permite a deposição de toneladas de areia vinda do mar, fruto de maresias lentas e marés pouco propícias, encurtando a área de banhos e diminuindo drasticamente a profundidade na zona leste, ou lameira. Um deles clarifica: "aquilo tem mesmo precisão de ser visto, a alagoa está cada vez mais baixa, qualquer dia é um rolo de mato molhado, aquilo bastava tirar a areia onde a água corre para o mar, ali nos urinos" (Inquirido $\left.\mathrm{n}^{\mathrm{o}} 14\right)$.

Os resultados obtidos nos inquéritos e na recolha documental confirmam a existência de problemas relacionados com as condições ambientais da Lagoa e com as condições da pesca, apresentadas na Tabela 1. Esta listagem foi apresentada aos diferentes atoreschave durante o workshop para que eles realizassem a sua priorização, num processo de votação, a fim de se encontrarem os três itens mais votados e que, considerados os mais relevantes, fossem sujeitos a discussão e apresentação de propostas de solução igualmente por sufrágio. 


\subsection{O Workshop e seus resultados}

Vinte e um atores-chave estiveram presentes no workshop. Incluíam pescadores da lagoa (16), AAPACSACV - Associação de Armadores da Pesca Artesanal e do Cerco do Sudoeste Alentejano e Costa Vicentina (2), APA - Agência Portuguesa do Ambiente (1), ICNF (0), Quercus (1), JFSA - Junta de Freguesia de Santo André (1), CMSC (0), Agentes económicos locais (2).

No início foi apresentado um enquadramento da lagoa e os principais problemas a que esta estava sujeita, que tinham resultado dos trabalhos anteriormente desenvolvidos. Posteriormente, os participantes orga- nizados em grupos de trabalho mais pequenos tiveram oportunidade de analisar a listagem dos problemas principais (Tabela 1). Daí deviam selecionar os três problemas mais votados, com vista ao apuramento das respectivas soluções. $O$ passo seguinte consistiu na discussão por cada grupo de trabalho, para que apresentassem soluções até um número de cinco para cada um dos problemas mais votados, soluções que mereceram posteriormente o voto individual dos atores conforme o apresentado na tabela 2.

Não obstante a ausência do ICNF no workshop, os resultados foram-lhe transmitidos em tempo devido, para conhecimento e apreciação.

Tabela 1: Problemas na Lagoa de Santo André resultantes dos inquéritos e da recolha documental.

\section{Problemas de Qualidade do Ambiente}

$1^{\mathrm{o}}$ - Excessivo assoreamento.

$2^{\circ}$ - A falta de limpeza dos cursos de água que nela desaguam, não permitindo o seu enchimento em plenitude.

$3^{\circ}$ - A falta de fiscalização relativa a descargas de efluentes nas suas ribeiras, com a consequente deposição de matéria lodosa no fundo.

$4^{\circ}$ - A abertura ao mar em condições pouco estudadas, em que o fecho da lagoa permite a deposição de toneladas de areia vinda do mar, que provoca uma diminuição da área de banhos e da profundidade na zona leste, ou lameira.

$5^{\circ}$ - Ausência de Projetos / Planos de desenvolvimento local.

\section{Problemas da Pesca}

$6^{\circ}$ - Existência de falta de diálogo entre, os atores-chave locais.

$7^{\circ}$ - Sustentabilidade económica da pesca (baixo custo do pescado).

$8^{\circ}$ - A Regulamentação da pesca.

$8.1^{\circ}$ - A acomodação das suas redes e aparelhos.

$8.2^{\circ}$ - Melhor definição do modo como é permitida a pesca, nomeadamente possível alteração nas dimensões e número de aparelhos autorizados.

$8.3^{\circ}$ - Alteração do período permitido para a pesca do remolhão (atualmente, uma hora antes e depois do por do Sol).

$8.4^{\circ}$ - Alteração do período de defeso.

$8.5^{\circ}$ - Melhor definição do perímetro delimitado de pesca

\subsection{Propostas de Solução e Recomendações}

Este tipo de trabalho de investigação, com envolvimento e participação da população local, espelha, pela natureza da sua temática, não só a importância dos processos de divulgação e da sensibilização à participação da população local nas decisões para a gestão ambiental das zonas costeiras, como traduz a resultante dessa mesma envolvência, com inegáveis proveitos para todos.

De um modo geral, as grandes transformações operadas no seio das comunidades são fruto de tendências e de uma visão cada vez mais voltadas para a globalização, em que os Estados, por força de estratégias e planos de pendor empresarial e económico, equacionam, muitas vezes, a requalificação de zonas de excelência ambien- tal e social, em áreas de grande potencial produtivo e/ou turístico.

Essas áreas, que se revestem de uma ancestralidade enriquecida pelos saberes tradicionais, ficam, por maioria de razão, em nome do progresso e do ordenamento territorial, irremediavelmente descaraterizadas, fruto do défice cultural, social, económico e da perda de riqueza etnográfica, muitas vezes irrecuperáveis, a que essas alterações estruturantes muitas vezes conduzem.

Num estudo desenvolvido por Vivacqua et al. (2009), estes autores referem serem inúmeros os desafios e obstáculos que têm sido observados nestes processos de gestão, em que é requerida a participação dos atoreschave no processo de decisão, dada a ausência de 
compromisso e pouca participação dos órgãos públicos, bem como a fraca participação da população local, que muitas vezes se ausenta dos trabalhos, contrariando o princípio da cidadania ativa e participativa, que estabelece que todos os planos de gestão elaborados pelos Estados devem ser desenvolvidos com a participação efetiva dos atores sociais envolvidos no processo.

O estudo em apreciação versa o debate académico sobre a viabilidade de implementação de estratégias alternativas relativas ao desenvolvimento em zonas costeiras protegidas, no cenário da globalização assimétrica, que caracteriza as sociedades modernas, em particular a zona do Estado de S. Catarina no Brasil. A linha de argumentação alude primeiramente a perspectiva de aplicação do conceito de desenvolvimento territorial sustentável ao processo em curso de criação de um sistema de gestão integrada e participativa do litoral. Numa outra abordagem, apresenta uma visão panorâmica do processo de normatização dos instrumentos utilizados no Sistema de Gestão de Unidades de Conservação no Brasil, oferecendo uma síntese do processo de construção do projeto de Gestão Integrada das Unidades de Conservação Marinho-Costeiras do Estado de Santa Catarina. Em seguida, houve que estudar o potencial contido na abordagem territorial do desenvolvimento para a consolidação do processo de integração no Plano Nacional de Gerenciamento Costeiro, tendo presente as diversas abordagens requeridas, entre as quais a participação de agentes e atores numa representação interessante do ponto de vista da ampliação da participação das comunidades locais na gestão do património natural e cultural costeiro.

Segundo Santos (2011), no seu trabalho sobre a sustentabilidade relativa ao impacto da criação da Reserva Natural das Ilhas Berlengas (RNB), no seio da comunidade piscatória da cidade de Peniche, houve que modelar procedimentos e organizar uma estrutura de trabalho assente em entrevistas exploratórias feitas a pescadores, bem como a técnicos do ICNB (atualmente, ICNF), que permitiram em fase posterior caracterizar a realidade social encontrada no terreno, com vista ao encontro de soluções e conclusões para a gestão de eventuais conflitos. Relativamente a este estudo, no qual encontrámos similitude entre as duas realidades, a desta população e a da Lagoa de Santo André, tivemos em conta a sua abordagem à gestão dos recursos e sua sustentabilidade, face a um organismo tutelar, bem como seu contributo para o Estado da Arte.

Um outro projeto num contexto semelhante: o MARgov do Instituto do Mar (IMAR), visou capacitar agentes para a mudança, ao nível da governação sustentável dos oceanos, pelo reforço do diálogo entre os atores, assim como realçar a dimensão humana e social na gestão das áreas marinhas protegidas (AMP). Tendo como enfoque a resolução da problemática relativa à governança e à fraca participação dos atores locais na gestão do Parque

Tabela 2: Identificação dos três problemas principais e soluções propostas pelos atores-chave no workshop

\section{Três Problemas Mais Votados}

$1^{\circ}$ - Regulamentação da Pesca.

$2^{\circ}$ - Falta de diálogo entre os atores-chave.

$3^{\circ}$ - Excessivo assoreamento.

\section{Soluções Propostas - Regulamentação da Pesca}

$1^{\circ}$ - Começar a faina da pesca a 15 de setembro, até a abertura da lagoa ao mar

$2^{\circ}$ - Rever a regra da pesca do remolhão até às $22.00 \mathrm{~h}$

$3^{\circ}$ - Aumentar a altura das redes - nassas e tresmalho, para 2 panos $(4 \mathrm{~m})$ e permitir 40 a 60 nassas para os períodos autorizados (inicial e de continuidade)

$4^{\circ}$ - Delimitação e aumento do perímetro de pesca.

$5^{\circ}$ - Agilizar o Regulamento de Pesca adaptando-o à realidade.

\section{Soluções Propostas - Falta de Diálogo}

$1^{\text {o }}$ - Retomar o convívio do dia 1 de novembro para a promoção do diálogo, com o recomeço da caçada na lagoa neste dia de tradição.

$2^{\circ}$ - Gestão de diálogo pela autarquia.

\section{Soluções Propostas - Excessivo Assoreamento}

$1^{\circ}$ - Dragar as areias desde a zona da aberta até à Cabana do Peixe.

$2^{\circ}$ - Boas práticas agrícolas a montante da Bacia Hidrográfica.

$3^{\circ}$ - Arrasto antes da abertura ao mar. 
Marinho Professor Luiz Saldanha do Parque Natural da Arrábida, o projeto regista outro exemplo desenvolvido em Portugal sobre esta temática, tendo obtido resultados assinaláveis ao nível da capacitação de agentes para a governação sustentável dos oceanos, reforçando o diálogo ecossocial na resolução de conflitos, vincando as competências e a corresponsabilização de todos os atores na cogestão participada, modulando saberes e conhecimento, num processo de articulação entre os diversos tipos de conhecimento (tradicional, cultural, técnico-científico), bem como criando sinergias para fomentar a troca de saberes, experiências e boas práticas entre os diferentes atores, visando a construção de novo conhecimento para obtenção de soluções colaborativas (Vasconcelos et al., 2012).

No caso da Lagoa de Santo André, assistimos a um processo quase natural, de grande necessidade de ordenamento costeiro, tendo sido desenvolvido nos anos oitenta do século XX, um plano Diretor Municipal de ordenamento urbano que, em rigor, a CMSC, de parceria com o Ministério do Ambiente, executou de forma brilhante, segundo José Eduardo Evangelista Franco Cheis, vereador da edilidade à época, mas aquém das expectativas do desenvolvimento esperado pela população, a quem tinha sido prometida a execução de um plano de desenvolvimento sustentável, ambicioso e que traria mais-valias sociais, económicas e ambientais à região (Cheis, com. pess.).

Esta povoação tem a particularidade de ter no seu domínio territorial um espaço lagunar inserido na Reserva Natural das Lagoas de Santo André e Sancha, tendo sido neste enquadramento, espaço lagunar e povoação do mesmo nome, que centrámos este estudo, tendo como matriz a perceção das populações face à sustentabilidade das zonas costeiras.

\section{Considerações finais}

\subsection{Refletindo Sobre os Resultados}

A antiga povoação oferece agora um ar desolador e não se vislumbra no imediato que se altere este estado de coisas, carecendo esta zona de um projeto de recuperação que vise a sustentabilidade e o pendor ambiental e económico que dignifique a zona costeira e que com isso promova a equidade social.

No mesmo contexto de ordenamento, é criada a RNLSAS (Reserva Natural da Lagoa de Santo André e Sancha) e, posteriormente, o ICNF, entidade/autoridade que passa a determinar os novos procedimentos, no que à área protegida concerne. A pesca passa a ser regrada sob a chancela legislativa cujas determinações são veiculadas em editais de pesca todos os anos.

A pesca na lagoa continuou e continua, da forma que agora se apresenta. Foi criada a Zona de Pesca Profissional, os pescadores organizaram-se, asso- ciaram-se e, acima de tudo, interessaram-se não só pelos seus recursos, enquanto esta atividade lhes pode trazer algum proveito, como pela preservação da lagoa e das espécies que nela habitam.

Este estudo não encontra uma problemática derivada do conceito inicial, que apontava a deslocalização da povoação como fator determinante para que se perdesse, com isso, a tradição, os saberes e o legado da tradição oral, aliados à perda da identidade que caracterizava esta gente. A profunda alteração de paradigma, na qual se inclui a deslocalização desta povoação, é que foi determinante para que fosse esquecida a memória e a tradição, que agora se procura recuperar e preservar.

$\mathrm{Na}$ realidade, no âmbito do propósito da referida perceção das populações face à sustentabilidade, encontrámos neste estudo exploratório, matéria digna de nota no que à pesca da lagoa refere, mas também iniciativas autárquicas louváveis, para a preservação da identidade, dos saberes e tradição do povo antigo da lagoa.

Os pescadores são agora uma população envelhecida, vindos na sua maioria da área circundante, em detrimento de uma meia dúzia originária da Lagoa de Santo André, que lutam obstinadamente para que a pesca continue, para que seja possível trazer gente nova a esta faina antiga e para que a lagoa não morra, asfixiada em processos de ordenamento e conservação da natureza que, embora fundamentais para garantir a continuidade dos serviços dos ecossistemas, geram conflito com as populações locais devido a uma ausência de diálogo aberto entre as partes interessadas.

Os resultado dos inquéritos aos pescadores mostram a necessidade de maior discussão e maior envolvimento dos mesmos, desencantados com o estado a que se chegou, mormente pela falta de diálogo existente entre o ICNF e a sua representante, a AAPACSACV, conscientes de que, unidos e sendo ouvidos, pode muita coisa mudar e melhorar a bem do interesse geral, disponibilizando-se para estarem presentes sempre e quando instados a fazê-lo, para que alguns dos seus anseios pudessem ser ouvidos ou pudessem ser esclarecidos para um entendimento cabal das limitações impostas pelo ICNF, através dos seus Editais.

Algo na realidade mudou de forma inequívoca. Veja-se que, ao manterem-se cerca de trinta a trinta e cinco pescadores no ativo, pese embora o registo discutível das suas capturas, podemos concluir que o valor médio do total pescado por ano, se nos centrarmos apenas nos últimos três anos (os melhores), rondará as 13 toneladas/ano.

Se considerarmos um valor médio de $10 €$, o preço $/ \mathrm{kg}$ do pescado no seu todo, chegamos ao seguinte raciocínio: $1300 / 35 \times 10 / 12=309 €$, o que é o rendimento mensal, sujeito a carga fiscal. Porém, 
frequentemente, tal não sucede, dado que grande parte do pescado entra diretamente na alimentação das famílias. Ou seja, o investimento em embarcações e aprestos, licenciamentos e outros custos também financiam generosamente esta arte antiga, não deixando morrer a tradição, sendo pouco compensatória em termos de proveitos, só sendo possível, porque, na sua maioria, os pescadores detêm outras fontes de rendimento para a sua subsistência.

Os pescadores pretendem que se criem condições para a acomodação das suas redes e aparelhos e que sejam estudadas alterações ao regulamento da pesca, nomeadamente no que se refere às dimensões e número de aparelhos autorizados, à alteração do período de defeso, ao perímetro delimitado de pesca; pretendem também que se olhe para as condições de equilíbrio do ecossistema, permitindo a intervenção sustentável do homem para o seu restabelecimento; e pretendem ainda que, acima de tudo, o saber científico não descure a sabedoria popular e saibam comunicar sem complexos, para que se não perca esta joia lagunar, berço milenar de tradições, de um equilíbrio extraordinário e fonte de rendimento para os homens e mulheres que souberam, em tempos idos, dignificar a arte da pesca na lagoa, levando o seu pescado ao reconhecimento da sua superior qualidade, apreciado aquém e além-fronteiras.

Em síntese, existe na comunidade piscatória a consciência e uma preocupação ambiental no que ao equilíbrio e manutenção do ecossistema lagunar diz respeito, a par de uma preocupação económica que visa a recuperação do espaço envolvente e uma outra, porventura mais premente tendo em conta a sua atividade, que aponta a regulamentação da pesca, que consideram lesiva dos seus interesses, acentuando a manifesta falta de diálogo entre a sua associação e o ICNF.

O problema ligado à pesca surge de forma abrangente, multidisciplinar, ou seja: ele centra-se em três eixos, nomeadamente, a pesca, o ambiente e o desenvolvimento económico, que os atores-chave do referido workshop elegeram como prioritários.

O ICNF refuta parte das propostas colocadas pelos pescadores, considerando algumas dignas de nota, mas diz-se desencantado pela incapacidade criada no processo de comunicação entre os atores.

\subsection{Sugestões de Propostas Futuras}

Para que fossem aclaradas as discussões sobre este relato, entendemos apresentar um conjunto de medidas a serem implementadas, de forma a melhorar a gestão integrada desta zona costeira:

* O desenvolvimento de uma estratégia ou um plano integrador de cariz ambiental, social e económico, que promova a qualidade e sustentabilidade a todos os níveis desta zona do país de reconhecido potencial;
* A requalificação da bacia hidrográfica, ao nível da recuperação da área volumétrica da lagoa, bem como o restabelecimento de procedimentos que evitem a degradação das suas águas em processos de eutrofização, promovendo regras e fiscalização a montante.

Propõe-se ainda que, no terreno, o ICNF possa articular a melhor solução e procedimentos que promovam, respetivamente:

* A fiscalização e controlo de efluentes lançados nas linhas de água que desaguam na lagoa;

* A execução de boas práticas agrícolas, bem como a intervenção e acompanhamento dos trabalhos ao nível da limpeza de margens de cursos de água ou outros que, potencialmente, possam provocar o transporte de matéria residual para a lagoa;

* O diálogo e participação efetiva de todos os atoreschave na elaboração de regulamentos de pesca profissional;

* A avaliação de opiniões de cariz popular, sustentadas em saberes ancestrais, quer sobre a pesca, quer sobre o ambiente;

* O esclarecimento oportuno dos pescadores sobre a determinação de atitudes legislativas e outras ações de formação que possam, na ausência de informação, poder gerar conflitos;

* A comunicação, na vertente relativa à eficiência e eficácia, para que se não perca o diálogo;

- Pugnar pelos legítimos interesses do ambiente e pela preservação e melhoria da qualidade do espelho de água lagunar;

* A resolução da problemática pesca e pescadores, consensualizando soluções que satisfaçam as partes, propondo, pela justeza argumentativa, alterações ao quadro legislativo, sempre que o momento o justifique, tornando os modelos harmonizados, não estáticos e não redutores;

* A participação de entidade exterior que modere a discussão dos problemas ou que facilite a comunicação entre os atores-chave, no sentido da resolução de diferendos resultantes de falha na comunicação entre as partes.

As regras, normas e a consciencialização para a questão ambiental, carecem de um sentir instituído por práticas didácticas e pedagógicas com alcance global, que envolva todos os atores, numa ética ambiental e de responsabilidade social, acrescida da participação dos Estados em termos de legislação, que conduza aos princípios da prevenção, do desenvolvimento sustentável, e da defesa dos recursos naturais.

"A Constituição portuguesa estabelece um conjunto de princípios fundamentais em matéria de ambiente como seja o da prevenção, o do desenvolvimento 
sustentável, o do aproveitamento racional dos recursos, um processo forçosamente lento de consciencialização social e de integração efetiva no ordenamento jurídico de novas ideias" (Silva, 2002).

\section{3. Conclusões}

A perceção das populações locais face à sustentabilidade das zonas costeiras, no caso da Lagoa de Santo André, foi o tema escolhido para a elaboração deste estudo exploratório.

A conclusão final deste projeto demonstra inequivocamente que a perceção das populações face à sustentabilidade da zona costeira em estudo, não detém a esperada correspondência e situa-se num nível de enorme contestação, relativamente à gestão do ICNF, o que, no entender do explorador, deriva de uma má estratégia ao nível da comunicação entre os atoreschave do processo.

Ou seja, por esse motivo, instalou-se o descrédito na população relativamente a projectos em geral e aos que visem a preservação ambiental no que ao espelho de água se refere, assim como à implementação de iniciativas que potenciem o desenvolvimento

\section{Referências bibliográficas}

Bogdan, R.; Biklen, S. (1994) - Características da Investigação Qualitativa. In: Investigação Qualitativa em Educação: Uma Introdução à Teoria e aos Métodos, pp.47-51, Porto Editora, Porto, Portugal. ISBN: 978-9720341129. (disponível em http://www.sepq.org.br/IIsipeq/ anais/pdf/poster1/05.pdf).

Dias, J.A.; Mahiques, M.M.; Cearreta, A. (2012) - Gestão Costeira: Resultado de uma Relação Dúbia entre o Homem e a Natureza. Revista da Gestão Costeira Integrada, 12(1):3-6. DOI: 10.5894/rgci331.

ERENA (2005) - Plano de Ordenamento da Reserva Natural das Lagoas de Santo André e da Sancha. $1^{a}$ fase - Caracterização. Parte 1: Estudos de base. 130 p., ERENA - Ordenamento e Gestão de Recursos Naturais, Lisboa, Portugal. Não Publicado.

Escoval, A.; Silva, C.T. da; Freitas, C.; Pereira, F.M.; Bernardo, J.M.; Matias, J.; Fonseca, L.C. (2003) - O Homem, a Terra e a Lagoa. 40 p., Cadernos do Património, Câmara Municipal de Santiago do Cacém, Santiago do Cacém, Portugal.

Presidência do Conselho de Ministros (2009) - Resolução do Conselho de Ministros n. ${ }^{\circ}$ 82/2009 [Estratégia Nacional para a Gestão Integrada da Zona Costeira]. Diário da República [8 de Setembro], 1. ${ }^{\mathrm{a}}$ série, 174:6056-6088, Lisboa, Portugal. Disponível em: http://dre.pt/pdf1sdip/2009/09/17400/060560 6088 .pdf.

Fonseca, L. Cancela da.; Bernardo, J.M.; Costa, A.M.; Cruz, T. (1993) - Lagoa de Santo André: Sistema Litoral Produtivo mas Frágil. Actas do Encontro sobre a Lagoa de Santo André, pp. 29-42, Associação Cultural de Santiago do Cacém, Portugal.

Gerhardt, C.H.; Almeida, J. (2005) - A dialética dos campos sociais na interpretação da problemática ambiental: uma análise crítica a partir de diferentes leituras sobre os problemas ambientais. Ambiente \& Sociedade, 8(2):53-84, Campinas, SP, Brasil. DOI: 10.1590/S1414-753X2005000200004.

Ministério da Agricultura, do Mar, do Ambiente e do Ordenamento do Território (2012) - Decreto-Lei $n .^{\circ}$ 135/2012 [Orgânica, económico desta região ou que promovam a informação sobre a atividade de seu interesse, a pesca na lagoa.

Podemos concluir estar em presença de um caleidoscópio de problemas que são sentidos por todas as partes envolvidas no processo da sustentabilidade desta zona costeira e que são aguardadas, com premência, decisões e projetos emanados da gestão pública e organismos ao mais alto nível, tendo sido apresentadas neste estudo exploratório, possíveis soluções que podem levar a uma melhor gestão desta zona da orla marítima no quadro da área lagunar.

Realçamos a importância de ser equacionada a participação de uma entidade facilitadora, que modere a discussão dos problemas ou que facilite a gestão de conflitos entre os atores-chave, concluindo-se ser a falha na comunicação entre atores, o principal problema encontrado pelo explorador neste projeto.

No quadro de desenvolvimentos futuros, é reconhecida a premência de estudos continuados que avaliem e monitorizem a efetivação de editais e o grau de satisfação das partes envolvidas no processo, com enfoque para a comunidade piscatória da Lagoa de Santo André.

Estatutos e Organograma do ICNF]. Diário da República [29 de junho de 2012], 1. a série,125:3326-3330, Lisboa, Portugal. Disponível em http://dre.pt/pdf1sdip/2012/06/12500/03326 03330.pdf.

Leal, C.R.B. (2012) - Comunidades tradicionais da zona costeira cearense. Uma Análise da Percepção dos Diferentes Atores Sociais de Canoa Quebrada e Vila do Estevão Sobre o Processo de Modernização Vivenciado por Essas Populações. 151p., Dissertação de Mestrado, Universidade Federal do Ceará, Fortaleza, CE, Brasil. Disponível em http://www.repositorio. ufc.br/handle/riufc/4022

Luyet, V.: Schlaepfer, R.; Parlange, M.B.; Buttler, A. (2012) - A framework to implement Stakeholder participation in environmental projects, Journal of Environmental Management, 111:213-219. DOI: 10.1016/j.jenvman.2012.06.026

Madeira, J. (1993) - Santo André no século XIX: O Homem e a Lagoa. Actas do Encontro sobre a Lagoa de Santo André, pp. 45-64, Associação Cultural de Santiago do Cacém, Santiago do Cacém, Portugal.

Ministério da Agricultura, Desenvolvimento Rural e Pescas (2004) Portaria $n^{\circ} 86 / 2004$ [Zona de Pesca Profissional na Lagoa de Santo André]. Diário da República [8 de Janeiro de 2004], $2^{\text {a }}$ Série, 6:227-229, Lisboa, Portugal. Disponível em http://dre.pt/pdf2sdip/2004/01/006000000/0022700229.pdf

Ministério do Ambiente e do Ordenamento do Território (2000) Decreto Regulamentar $n^{\circ}$ 10/2000 [Reserva Natural das Lagoas de Santo André e Sancha]. Diário da República [22 de Agosto de 2000], $1^{\text {a }}$ Série-B, 193:4240-4245, Lisboa, Portugal. Disponível em http://www.dre.pt/pdfgratis/2000/08/193B00.PDF

Quivy, R.; Campenhoudt, L.V. (1998). - Manual de Investigação em Ciências Sociais. [tradução do original francês Manuel de 
recherche en sciences sociales, Dunod, Paris, 1995]. 284 p., Gradiva, Lisboa, Portugal. ISBN: 978-9726622758

Santos, A. (2011) - O Papel dos Conhecimentos e dos Modos de Vida Local no Desenvolvimento Sustentável, Estudo Exploratório Sobre o Impacto da Reserva Natural das Ilhas Berlengas na Comunidade Piscatória. 135 p., Dissertação de Mestrado em Cidadania Ambiental e Participação, Universidade Aberta, Lisboa, Portugal. Disponível em https://repositorio aberto.uab.pt/handle/10400.2/1938

Serrano, G.P. (2004) - Investigación Cualitativa I: Retos e Interrogantes - Métodos. 232 p., La Muralla, Madrid, Espanha. ISBN: 978-8471336286.

Silva, A.M. (1869) - Annaes do Municipio de Sant'iago de Cacem. 280 p., Imprensa Nacional, Lisboa. Portugal. Disponível em https://archive.org/details/annaesdomunicipi00silv

Silva, V.P. (2002) - Verde Cor de Direito. Lições de Direito do Ambiente. 294 p., Livraria Almedina, Coimbra, Portugal. ISBN: 9724016528.

Vasconcelos, L.; Caser, U.; Pereira. M.J.; Gonçalves, G.; Sá, R. (2012) - MARGOV Building Social Sustainability. Journal of
Coastal Conservation, 16(4):16:523-530, DOI: 10.1007/s11852012-0189-0.

Vasconcelos, L.T. (2006) - O Exercício da Cidadania pela Participação Popular. In: Um Outro Mundo é Possivel...mas Não Será Fácil!, pp.21-27, Edições Colibri, Lisboa, Portugal. ISBN: 9727726631.

Vasconcelos, L.T., Caser, U. (2011) - Participação e Métodos Interativos na Decisão Ambiental - Teoria e Prática. UAB, maio 2011, 16 p., Lisboa, Portugal. Não publicado

Vivacqua, M.; Santos R.; Vieira, P.F. (2009) - Governança territorial em zonas costeiras protegidas: uma avaliação exploratória da experiência catarinense. Desenvolvimento $e$ Meio Ambiente (ISSN: 1518-952X), 19:159-171, Editora UFPR, Curitiba, PR, Brasil. Disponível em http://ojs.c3sl.ufpr.br/ ojs/index.php/made/article/viewFile/13759/10891

Wakashima, M.A.; Capellari, B. (2010) - Globalização e Deslocalização, Uma Análise do Crescimento do Turismo Residencial do Mediterrâneo Espanhol e no Litoral Nordestino e Seus Impactos Socioambientais, 11 p., Revista Iniciação (ISSN: 2179-474X), 1(1):33-43, São Paulo, SP, Brasil. Disponível em http://www1.sp.senac.br/hotsites/blogs/revistainiciacao/wp-cont ent/uploads/2013/07/9.pdf

O artigo "Perceção das populações locais face à sustentabilidade dos serviços das zonas costeiras: o caso da Lagoa de Santo André, Portugal", de Santinhos et al. (2014), tem informação de suporte disponível on-line em http://www.aprh.pt/rgci/rgci-472_Santinhos_SuplMat.pdf

This article contains supporting information online at http://www.aprh.pt/rgci/rgci-472_Santinhos_SuplMat.pdf 